\title{
El Salvador y Estados Unidos fortalecen su relación estratégica
}

La segunda década del siglo XXI comenzó en El Salvador teniendo como telón de fondo dos realidades diferenciadas, pero que se entrelazan: por un lado, la crisis económica, que se manifiesta en desempleo y alto costo de la vida; y por otro, la crisis de inseguridad, que nos distingue con uno de los índices de violencia más altos de la región. Es en este telón donde debemos ubicar lo que va aconteciendo en el país y desde el cual el Gobierno debe intentar bosquejar un futuro más alentador para la población salvadoreña.

A principios de año, el PNUD hizo público el informe sobre desarrollo humano en El Salvador para 2010. Como novedad con respecto a anteriores ediciones, el informe analiza el modelo de desarrollo económico que se ha seguido y aplicado en los últimos sesenta años. El documento del PNUD afirma que dicho modelo ha sido incapaz de generar crecimiento económico, mucho menos bienestar para la población. Y la razón de ello es simple: no ha tenido como eje central el despliegue de las capacidades de la gente. Así, diecinueve años después de firmada la paz, las condiciones económicas y sociales no son muy diferentes a las que prevalecían durante la guerra. A los problemas tradicionales de bajo crecimiento, subempleo y baja recaudación fiscal, se suma la inseguridad. En esta línea, el informe plantea una propuesta en la que se enfatiza la necesidad de que la política social pase a constituirse en uno de los principales ejes de desarrollo del país.

Aunque el Gobierno de Mauricio Funes ha declarado en múltiples ocasiones que la inversión social es una de sus prioridades (de hecho, fue una de sus principales ofertas electorales), esta no podrá realizarse mientras se mantengan las actuales condiciones fiscales. Desde hace varios años, el déficit fiscal se ha cubierto con endeudamiento público, el cual ya ha llegado a niveles insostenibles. El Salvador cerró 2010 con una deuda de aproximadamente de 11000450 millones de dólares, que representan más del 50\% del PIB. Dada la dificultad de incrementar los ingresos vía una reforma fiscal, se está trabajando en la racionalización del gasto público. Tanto el Banco Mundial como el Banco Interamericano de Desarrollo (BID) han insistido en la necesidad de reducir los subsidios a la electricidad, gas licuado, agua y transporte público.

\section{Focalizar los subsidios}

El 2011 inició con la expectativa sobre la focalización del subsidio al gas licuado, anunciada el año anterior por el presidente Funes, considerada 
necesaria por un amplio abanico de actores de la sociedad (desde instancias ligadas a la gran empresa privada hasta analistas y organizaciones identificados con una orientación más progresista) y reivindicada por algunos economistas nacionales y por los organismos financieros internacionales desde el Gobierno de Elías Antonio Saca (2004-2009). La medida persigue reducir el déficit fiscal como parte del acuerdo Stand-By suscrito con el Fondo Monetario Internacional (FMI). Este acuerdo, que también retoma el Plan General Anticrisis del Gobierno de El Salvador, plantea "focalizar el gasto público en programas sociales y otros sectores de gran prioridad,

Deberán transcurrir varios meses para que la focalización del subsidio al gas se implemente con normalidad y pueda valorarse con objetividad si la medida constituye un ahorro para las arcas públicas sin afectar a la mayoría de la población, ya golpeada por la crisis. afianzar la situación fiscal a mediano plazo, encaminar la deuda pública por una trayectoria descendente firme y consolidar la estabilidad financiera". De este modo, el actual Gobierno da continuidad a la búsqueda de estabilidad macroeconómica de sus predecesores; en su caso, específicamente a través de la reducción del gasto público.

En un país como el nuestro, que no cuenta con registros confiables de variables económicas y sociales familiares, la tarea de focalizar un subsidio es muy compleja. A ello se debe que, en el primer trimestre del año, el Gobierno haya pospuesto en dos ocasiones la entrada en vigencia de la medida. Ahora se ha anunciado que entrará en vigor a partir de abril.

Más allá de las diversas opiniones y valoraciones sobre la focalización del subsidio, la mayoría de la población ve con temor la posibilidad de no ser receptora del beneficio y verse obligada a pagar hasta tres veces más del precio actual por el gas. Este temor es reforzado por los grandes medios de comunicación alineados con la oposición, que ven en la medida $-y$ en el titubeo para implementarla- la oportunidad de generarle costos políticos al Gobierno, especialmente al partido que lo llevó al poder. La administración Funes no la tendrá nada fácil. Deberán transcurrir varios meses para que la focalización del subsidio al gas se implemente con normalidad y pueda valorarse con objetividad si la medida constituye un ahorro para las arcas públicas sin afectar a la mayoría de la población, ya golpeada por la crisis.

\section{Pacto fiscal, ¿postergado o cancelado?}

Siempre en el contexto de la crisis económica, el Gobierno anunció en febrero su intención de llegar a un pacto fiscal, cuya discusión debía darse en el seno del Consejo Económico y Social (CES) integrado por representantes del Gobierno, de los sectores sociales organizados, de la academia y de la empresa privada. Como era de esperarse, la principal oposición a esta medida surgió desde el sector empresarial. En términos generales, los empresarios argumentaron que el Ejecutivo no persigue un pacto fiscal porque tiene ya previamente elaborada una propuesta de aumento de impuestos, y eso ya no es un pacto, sino una reforma tributaria. Siendo así, siempre bajo la lógica de los empresarios, el lugar idóneo para la discusión no era el Consejo, sino la Asamblea Legislativa. Según la empresa privada, aceptar la propues- 
ta del Gobierno de discutir la cuestión en el CES era prestarse a una manipulación; según el Ejecutivo, que la discusión se trasladara a la Asamblea significaría aceptar que no habrá pacto fiscal pronto, porque ningún partido político querrá pagar los costos políticos de una reforma fiscal en la víspera de elecciones. Estos dimes y diretes acapararon la atención de la agenda pública hasta el grado de que el arzobispo de San Salvador, monseñor Escobar Alas, pidió diálogo sensato sobre el asunto.

La oposición de la empresa privada no responde al espacio en que debe discutirse el pacto, sino a su percepción de los problemas económicos del país y a su actitud histórica frente a la cuestión de la desigualdad. Para la gran empresa privada, el problema en El Salvador no es la desigualdad, sino la pobreza. No se trata, según ellos, de redistribuir la riqueza existente, sino de generar condiciones desde todos los sectores para que exista un círculo virtuoso que potencie la economía de mercado. No debemos fijarnos en que unos pocos tienen mucho y muchos no tienen casi nada, dicen, sino en apoyar a los empresarios para que generen empleos e inversión, lo que redundará en beneficios para los de más escasos recursos. Esta postura la refuerzan diciendo que es un mito que los empresarios no contribuyen con el país. A su juicio, componen el sector que más da a El Salvador, y lo demuestran con las cantidades que aportan al fisco año con año. Lo que no mencionan los empresarios es lo que algunos de ellos no pagan por evasión fiscal; según un cálculo reciente, la evasión sumó más de 9000 millones de dólares para el período 2001-2009.

\author{
Los niveles de avaricia \\ y voracidad de los que tienen \\ mayor poder económico \\ alcanzan límites \\ escandalosos en nuestro país.
}

Nunca se ha escuchado a un gran empresario decir que es buen tiempo para aumentar los impuestos o los salarios de sus empleados. Por este tipo de actitudes y por la complicidad de los Gobiernos anteriores es que podemos entender las palabras del informe de desarrollo humano en El Salvador, 2010, del PNUD, en su sección IV: "El Salvador no ha podido construir hasta ahora una economía al servicio de la gente". Ni antes de la guerra, cuando la economía salvadoreña giraba en torno a la exportación de productos agrícolas (café, caña y algodón), ni en la actualidad, cuando la agricultura está prácticamente perdida y los bancos y los grandes centros comerciales se levantan donde antes florecían los cafetales, los empresarios han estado dispuestos a sacrificar sus márgenes de ganancia. Ni durante el siglo pasado, cuando catorce familias dominaban el país, ni hoy, cuando un cerrado y poderoso círculo de grupos empresariales determina en gran medida la lógica de la economía, la empresa privada ha mostrado solidaridad con el pueblo que sufre. Los niveles de avaricia y voracidad de los que tienen mayor poder económico alcanzan límites escandalosos en nuestro país.

Transcurrido el primer trimestre del año, el anuncio gubernamental sobre el pacto fiscal quedó solo en eso, en anuncio. ¿Le dobló el brazo la gran empresa privada o el Gobierno está repensando su estrategia? El desenlace revelará si esta administración se distingue de las anteriores o si sigue fa- 
voreciendo unas dinámicas económicas y de privilegio que profundizan la desigualdad.

\section{La inseguridad y la violencia que no remiten}

La crisis de inseguridad que vive El Salvador se refleja en las escandalosas estadísticas de hechos delictivos y, en especial, en la violación diaria del derecho a la vida. Sin embargo, ante las discrepancias de datos entre la Policía Nacional Civil y el Instituto de Medicina Legal, a estas alturas no sabemos a ciencia cierta el número de homicidios perpetrados en 2010. La Policía reporta 3985, mientras que Medicina Legal registra 4004 asesinatos durante el año recién pasado. Sea cual fuere la cifra correcta, la situación ha llegado a límites alarmantes y merece una intervención decidida y comprometida para combatir sus causas más profundas.

Particular atención merecen los homicidios cometidos contra mujeres. Organizaciones feministas denunciaron que al menos 160 de sus congéneres fueron asesinadas en el primer trimestre de 2011 en el país, aunque, según un monitoreo de la prensa nacional, la cifra asciende a 190 casos. En virtud de estos datos, El Salvador se ha convertido en uno de los países con más feminicidios a nivel mundial. Un informe conjunto de Las Mélidas, Las Dignas y la Organización de Mujeres Salvadoreñas (Ormusa) señala que en enero fueron asesinadas 66 mujeres; en febrero, 45; y en marzo, 49. Las más victimizadas son las mujeres entre los 18 y los 25 años, con 43 muertes; seguidas de las de 25 a 35 años de edad, con 41.

De acuerdo a diversas encuestas de percepción, la situación de inseguridad ha empeorado desde 2009, en coincidencia con la llegada del presidente Funes. Aunque el titular de la cartera de Justicia y Seguridad ha afirmado, en reiteradas ocasiones, que una prioridad de su gestión es trabajar en la prevención de la violencia, todo apunta a que el Gobierno, siguiendo la ruta de sus antecesores, se decantará por la lógica de la represión debido a la presión social y a la demanda de resultados tangibles. Bajo esa lógica, debe leerse la utilización excepcional del Ejército para acompañar a la Policía en patrullajes en zonas con altos índices de delincuencia, que se suma a la sanción de la Ley Antimaras en septiembre del año pasado.

La parálisis de la Fiscalía General de la República, que pareciera más interesada en dejar hacer al crimen organizado que en perseguirlo, llevó al presidente Funes a anunciar la intención de crear una comisión internacional para la investigación del crimen organizado, similar a la que ya opera en Guatemala. El anuncio no fue bien recibido tanto por la oposición como por el fiscal general, por lo que no pasó de ser -como otros- algo que levantó polvo pero no dejó huellas.

\section{La trascendencia de la visita de Barack Obama}

Marzo es siempre un mes especial para El Salvador. El 24, por resolución de la ONU y en homenaje al martirio de monseñor Romero, fue con- 
memorado como el Día Internacional del Derecho a la Verdad en relación con Violaciones Graves de los Derechos Humanos y de la Dignidad de las Víctimas. En el contexto de esta buena noticia, prácticamente silenciada por los grandes medios de comunicación nacionales, el país recibió al presidente de Estados Unidos, Barack Obama, en el marco de su pequeña gira por latinoamericana, que incluyó la visita previa a Chile y Brasil.

La llegada de Obama fue el centro de la agenda nacional desde varios días antes. Fundamentalmente, la discusión se centró en las razones por las que El Salvador fue elegido como uno de los tres países de la gira latinoamericana del presidente estadounidense. El Gobierno intentó sacarle todo el provecho posible al asunto publicitando la visita como un espaldarazo a la gestión del presidente Funes. Sus detractores la interpretaron como una simple acción de marcar territorio de dominio de la nación norteamericana. Otros argumentaron que el peso de los salvadoreños en los Estados Unidos era la razón principal. Pero más allá de ello, las mayores expectativas estaban puestas sobre la posibilidad de que Obama anunciara un paquete de ayuda económica ante la difícil situación que vive el país. Al final, todo quedó en poco o nada. Ante la ausencia de resultados sustanciales, los grandes medios destacaron lo que el mandatario estadounidense dijo o calló sobre el tema migratorio, la cooperación económica y la seguridad.

En lo que respecta a una posible reforma migratoria que legalice la residencia de los miles de indocumentados salvadoreños, el presidente Obama no dijo nada concreto. Los hechos más bien apuntan en la dirección contraria. En sus dos años de gobierno, se han realizado más deportaciones que en todos los años de su predecesor, George Bush. Es decir, el trato a los migrantes no solo no ha mejorado durante su mandato, sino que ha empeorado, por lo menos en lo que a deportaciones se refiere. En materia de coo-

El presidente Obama no es de las personas que no saben lo que hacen. Fue a la tumba de Romero sabiendo perfectamente quién era, cómo pensaba, a quiénes defendía y en contra de quiénes estuvo. peración económica para el país, todo se quedó en promesas. En realidad, el único aviso concreto que hizo el presidente Obama fue el de los 200 millones de dólares que se entregarán para reforzar la seguridad en el istmo -algo que no compete exclusivamente a El Salvador y que pudo haberse anunciado desde Estados Unidos-.

En realidad, el significado de la visita del presidente Obama no está en sus resultados, sino en lo que implica venir a El Salvador. Obama ha enviado un mensaje claro -y ese mensaje es político- sobre qué tipo de Gobiernos son los que considera sus aliados y con cuáles está dispuesto a consolidar alianzas. Las administraciones de Chile, Brasil y El Salvador son producto de la elección de sus ciudadanos, respetuosas de los derechos humanos, tienen una proyección social hacia los sectores tradicionalmente desfavorecidos y -pese a ese talante de izquierdas- no cuestionan de fondo el modelo del capitalismo globalizado. En este sentido, la visita de Obama fue el espaldarazo que el Gobierno de Funes pregonó. Si había que incluir a un país de Centroamérica en la gira, ese debía ser El Salvador por la situación 
política del resto de naciones del istmo. Funes ha dado muestras de independencia partidaria y eso ha sido visto con buenos ojos por la poderosa nación del Norte. Habrá que esperar si esta visita se traduce en apoyos concretos para la administración de Funes.

Pero si hablamos de lo acaecido durante la estancia de Obama en el país, el hecho más trascendental fue ocultado por los grandes medios de comunicación o fue abordado como noticia de relleno. Ese hecho fue su visita a la cripta de monseñor Romero, acontecimiento histórico sin precedentes: un presidente de Estados Unidos visitó la tumba del pastor excepcional, asesinado por quienes siempre se consideraron amigos y aliados de la nación norteamericana. El hecho fue un reconocimiento explícito y claro a la figura del arzobispo mártir y a su compromiso por la justicia. No se puede decir en ningún momento que fue una visita ingenua o de pura cortesía, como insinuó con malicia un diputado del partido cuyo fundador es el autor intelectual del martirio de monseñor. El presidente Obama no es de las personas que no saben lo que hacen. Fue a la tumba de Romero sabiendo perfectamente quién era, cómo pensaba, a quiénes defendía y en contra de quiénes estuvo. Es decir, la visita a la tumba significó reconocer la trayectoria de monseñor, el carácter de su martirio; en definitiva, implicó ponerse del lado suyo.

Así ha comenzado el presente año, con nubarrones económicos y de inseguridad que ensombrecen el panorama nacional, pero también con el tributo de los poderosos a la luz que aporta el legado de monseñor Romero, lo que solo puede entenderse como un triunfo de las víctimas de la historia. Ojalá esa luz ilumine de verdad el quehacer del Gobierno; ojalá la invocación al ejemplo del arzobispo mártir cobre cuerpo en hechos y acciones. 